\title{
Respiratory health effects of carbon black: a survey of European carbon black workers
}

Kerry Gardiner, Nicholas W Trethowan, J Malcolm Harrington, Charles E Rossiter, Ian A Calvert

\section{Abstract}

A study population of 3086 employees was identified in 18 carbon black production plants in seven European countries. Respiratory health questionnaires, spirometry, and chest radiographs were used to estimate effects on health and personal monitoring procedures were employed to measure current exposure to inspirable and respirable dust along with sulphur and carbon monoxide. The low concentrations of gaseous contaminants made the generation of their current and cumulative exposure indices impossible. Low responses from some plants restricted the final analysis to 1742 employees in 15 plants (81\% response rate) for respiratory symptoms and spirometry, and 1096 chest radiographs from 10 plants $(74 \%$ response rate). In total, 1298 respirable and 1317 inspirable dust samples, as well as 1301 sulphur dioxide and 1322 carbon monoxide samples were collected. This study is the first to include a comprehensive and concurrent assessment of occupational exposure to carbon black dust and its associated gaseous contaminants. Cough, sputum, and the symptoms of chronic bronchitis were found to be associated with increasing indices of current exposure. Lung function tests also showed small decreases in relation to increasing dust exposure in both smokers and nonsmokers. Nearly $25 \%$ of the chest radiographs showed small opacities of category $0 / 1$ or greater. These were strongly associated with indices of cumulative dust exposure. The

Institute of Occupational Health, University of Birmingham, University Road West, Birmingham B15 2TT

K Gardiner, N W Trethowan, J M Harrington, I A Calvert

10 Mynchen Road, Knotty Green, Beaconsfield, Bucks HP9 2AS

C E Rossiter findings are consistent with a non-irritant effect of carbon black dust on the airways combined with dust retention in the lungs. Further cross sectional studies are planned to investigate whether long term exposure to carbon black dust causes damage to the lung parenchyma.

(British Fournal of Industrial Medicine 1993;50:1082-1096)

Carbon black has been produced in one form or another for over two thousand years. The Chinese and Hindus used it as a colourant for ink and lacquers and produced it by burning animal and vegetable oil in porcelain pots. ${ }^{1}$ The Romans manufactured carbon black, which they used for murals and paintings. Commercial carbon black production for printing inks began in Pennsylvania (USA) in 1840, but the discovery at the beginning of the 20th century that carbon black was a valuable reinforcing filler for rubber, extended its uses. New methods of production-primarily the oil furnace process - has increased annual world wide production to over six million tonnes. ${ }^{2}$ Twenty per cent of this output comes from 20 plants in Western Europe (18 of these plants were members of the European Carbon Black Committee (ECBC) at the time of this study).

In most carbon black processes, a liquid or gaseous hydrocarbon feedstock is pyrolysed at $1300-1850^{\circ} \mathrm{C} .^{3}$ The resultant molecular fragments polymerise in the vapour phase to polycyclic aromatic species that condense to form liquid nuclei. Subsequent carbon deposition and coalescence gives spherical particles with diameters from 5 to $50 \mathrm{~nm}$ (furnace and channel process) up to $500 \mathrm{~nm}$ (thermal process). These primary particles form aggregates that agglomerate leading to larger visible fluffy particles. Products with differing specifications can thus be obtained from each carbon black process although there is a degree of overlap. The oil furnace process is the most versatile and therefore is usually the method of manufacture (17 out of 20 European plants use only the furnace process). In general, there are a number of grades 
of carbon black that are produced almost constantly (tyre grades), with other speciality grades being produced as and when required, however, almost all grades contain $95 \%-99.5 \%$ elemental carbon. The remainder are elements like sulphur, hydrogen, oxygen, nitrogen, and trace metals. ${ }^{4}$ Organic material can be extracted by solvents with part of the extract being polynuclear aromatics. ${ }^{5}$ The exact composition depends not only on the process but also on the nature and origin of the feedstock.

The crucial health questions relating to occupational exposure to carbon black concern the possibility that the airborne particles might cause irritant, fibrotic, or carcinogenic pulmonary effects.

A few studies have investigated the amounts of exposure to airborne particulates in the manufacturing industry. The first reported was in 1948 when two factories in Texas were evaluated and average concentrations of 23 and $33 \mathrm{mg} . \mathrm{m}^{-3}$ were found $^{3}$ through to the two most comprehensive studies by Smith and Musch ${ }^{6}$ and Gardiner and coworkers $^{3}$ where exposures an order of magnitude lower than those found in the Texas plants were reported. A more extensive review is presented elsewhere. ${ }^{3}$

The health effects of exposure to carbon particulates have been investigated since the turn of the century. ${ }^{78}$ The definition of the carbon dust presented in these papers is such that one can be reasonably confident that the particulates being described are not in fact carbon black as defined in the introduction. The first published report specifically assessing the adverse effects of carbon black was an inhalation study on five rabbits conducted by Borchardt and published in 1929.9 The first published report on human morbidity was by Gartner and Brauss in 1951 when they concluded that the inhalation of carbon black may produce radiographic changes analogous to pneumoconiosis ${ }^{10}$ and this was supported by Meiklejohn. ${ }^{11}{ }^{12}$ Some subsequent morbidity studies have been published with the two most recent being of greatest scientific value ${ }^{13}{ }^{14}$; this being due to the size of the populations studied and the scientific methods used. The European workforce was investigated by Crosbie in 1986 (spirometry, small format $x$ ray films, and a limited respiratory questionnaire $)^{13}$ and the American in 1988 (spirometry) ${ }^{14}$ with results for both, in the main, being negative. The Crosbie study included 19 plants, 18 located in western Europe and one in the United States of America. ${ }^{13}$ The difference between that population and the one we investigated and report here is that one factory has closed in the United Kingdom and an additional factory in Germany, not included in the Crosbie study, was included in ours. Also, no plants in the United
States were included in the investigation reported here. As there is, however, generally a low turnover of staff (about $5 \%$ a year) it is likely that a large proportion of the workforces were participants in both studies.

As a result of the variability in the techniques of medical assessment used; quality of characterising exposure, characterisation or elimination of either previous or concurrent confounding factors and the sizes of populations investigated the results of the various published morbidity studies are equivocal and not unsurprisingly conflicting. This is also true for the few mortality studies. ${ }^{15-20}$ Reviews of both morbidity and mortality will be presented in greater detail elsewhere. Thus it was decided to re-examine the European workforce (in ECBC member companies) with accurate and valid measures of current exposure for two dust size fractions (inspirable and respirable), sulphur dioxide, and carbon monoxide combined with health effect measurements taken at the same time and designed to achieve similar accuracy and repeatability.

\section{Materials and methods}

The study population comprises all workers currently employed for more than one month in 18 plants in Europe belonging to four companies. The plants are located in the United Kingdom (two), France (three), the Netherlands (two), Germany (five), Sweden (one), Italy (three) and Spain (two). The study, carried out between June 1987 and June 1989 was planned as the first of four such cross sectional environmental and respiratory morbidity surveys to be conducted over a decade to investigate morbidity effects longitudinally. As well as measuring personal exposure to the two dust fractions and two gases, the survey was designed to review the health of every employee by means of a questionnaire, spirometry, and chest radiography.

\section{STUDY ORGANISATION}

The exposure and health effects measures were to be carried out at each plant by personnel employed at the plant. The study was designed, co-ordinated, and supervised by us, and we produced a detailed study training manual and trained the relevant staff. The manual contained instructions on general study administration, details of all equipment needed, and methods of environmental measurements. These personnel received a two day training course before the study began and each plant was visited by the study team at least twice during the survey to ensure that the procedures were undertaken appropriately. Further checks on quality were undertaken on receipt of samples or results and unsatisfactory or incomplete returns were rejected and repeated. 


\section{STUDY SUBJECTS}

Eligible participants were identified from plant personnel records. Contract employees, as well as temporary or part time workers were excluded. All other employees were registered irrespective of their carbon black exposure. An anonymous register of 3086 workers was thus compiled and kept at the research co-ordinating centre.

\section{HEALTH QUESTIONNAIRE}

The questionnaire was designed to find the prevalence of respiratory and other symptoms, collect information on smoking habits and previous illness, as well as current and past occupation including past exposure to specific respiratory hazards. It was based on the Medical Research Council respiratory questionnaire with additional questions on cardiac and skin disorders. Occupational exposure histories in the plant were taken by asking the participant to select job titles from a list covering all jobs (table 1). The questionnaire was designed for self administration, translated into the relevant local language, and then back translated to ensure correctness of meaning. The completed questionnaire was brought by each participant to the health and spirometric examination.

\section{SPIROMETRY}

Lung function tests were carried out by the company medical officer at each plant with a properly maintained Vitalograph $S$ model dry wedge spirometer calibrated with a precision 1 litre syringe. Measurements of forced vital capacity (FVC), forced expiratory volume in one second $\left(\mathrm{FEV}_{1}\right)$, and forced expiratory flow during the mid$50 \%$ of expiration $\left(\mathrm{FEF}_{25-75}\right)$, were undertaken to a strict procedure and in accordance with the criteria of the American Thoracic Society. ${ }^{21}$

\section{CHEST RADIOGRAPHS}

Full size $(40 \times 40 \mathrm{~cm})$ films were requested from local radiographic services, to be taken according to the techniques specified by the International

\section{Table 1 Agreed job categories and job titles}

\begin{tabular}{lrl}
\hline fob categories & fob number & Fob title \\
\hline A & 1 & Administration area workers \\
B & 2 & Laboratory assistant \\
& 3 & Instrument mechanic \\
C & 4 & Electrician \\
& 5 & Process control operator \\
& 6 & Process foreman \\
& 7 & Fitter \\
& 8 & Welder \\
D & 9 & Furnace operator \\
& 10 & Process operator \\
E & 11 & Conveyor operator \\
& 12 & Warehouse packer/shipping \\
& 13 & Cleaner (not office) \\
\hline
\end{tabular}

Labour Office (ILO) 1980 international classification of radiographs for pneumoconioses ${ }^{22}$ (a number of services could only provide 14 inch $\times$ 17 inch films). Details of the procedures and quality required were specified in a manual provided to the radiographic service. The films were independently read by three trained and experienced readers with the 1980 ILO classification and standard reading procedures such as trigger films. All readers were blind to the exposure of the subjects whose radiographs they were assessing.

\section{QUALITY CONTROL}

Samples of questionnaires, spirometry, and radiographs were sent to the Institute of Occupational Health (as coordinating centre) in advance of the main survey to ensure accuracy, quality, and completeness. Data that did not meet the survey criteria were rejected and repeat measurements (except for chest radiographs) were requested. Additional visits to plants by the survey teams were initiated in the event of serious problems.

\section{OCCUPATIONAL EXPOSURE MEASUREMENTS}

The variability of the particle size (aerodynamic diameter) of carbon black to which workers are exposed in its manufacture is great ${ }^{32324}$ and therefore measures of exposure to both respirable and inspirable (total inhalable) dust were required. ${ }^{25} 26$ The respirable dust was measured with the SIMPEDS cyclone $\mathrm{e}^{26-28}$ and inspirable dust with the Institute of Occupational Medicine (IOM) head. ${ }^{29}$ The production of carbon black also results in a production gas, which contains large quantities of carbon monoxide. Most plants have a power station that burns the production gas and thereby generates a purge or waste gas rich in sulphur dioxide from the hydrogen sulphide present in the production gas. Both gases were actively sampled with long term colorimetric tubes. Carbon dioxide and sulphur dioxide measurements were taken due to their potential adverse effect on cardiac and respiratory conditions respectively.

To ensure both representative and random personal sampling, workers were split into five groups according to their job title (function) and then a proportion of each group (chosen to give $90 \%$ confidence of sampling an individual in the top $10 \%$ ) was randomly chosen. The chosen workers from the five groups were then randomised and placed on a sampling register, for both dust fractions, both gases, and for each of the 18 plants. Those who left the company or were permanently unavailable were replaced by workers randomly selected from the same job category. The quality of the data was ensured by training sessions for the plant personnel, plant visits, and rigorous quality control at the Institute of Occupational Health. The details of the 
sampling strategy etc are reported elsewhere for dusts and gases. ${ }^{34}$

Because of the large number of zero and trace values for the sulphur dioxide and carbon monoxide data, it was not possible either to determine distributional form or to generate exposure indices. The dust data, however, were lognormally distributed and geometric means and geometric SDs were therefore calculated for each of the five job categories within all 18 plants. The geometric means were ranked in ascending order and suitable cut off points were chosen before the analysis of the results to ensure adequate numbers of workers in each of the exposure groups

Cumulative exposure indices were calculated for each worker by multiplying the geometric mean of the relevant combination of plant and job category by the duration in months that worker had spent in each of the categories within each plant. A worker's values were then summated and expressed in terms of mg.months.m..$^{-3}$ As with the current exposure indices, the values for all of the participants were ranked in ascending order and suitable cut off points were chosen. This method has been used previously in the respiratory morbidity paper of Robertson et al. ${ }^{14}$

\section{STATISTICAL ANALYSIS}

The symptom data was largely of binary form (yes or no). After simple cross tabulations of symptoms against exposure the data were analysed with a multiple logistic regression of effect against exposure while controlling for potential confounding factors such as age, sex, smoking, and previous workplace exposure to respiratory hazards.

Lung function results were compared with the European Community coal and steel reference (ECCS) values ${ }^{30}$ and examined as percentage predicted. Multiple linear regression was then used to assess the relation between lung function and indices of exposure, adjusting for potential confounding factors.

For the chest radiographs, cross tabulations of $x$ ray film reading score and exposure were supplemented by logistic regression.

\section{Results}

STUDY POPULATION CHARACTERISTICS

A total of 3086 employees from 18 plants were eligible to participate in the study. In the event, through a combination of logistical difficulties and personal rejection the overall response rate was $71 \%$ with a range of $42 \%$ to $96 \%$ between plants. To minimise possible non-response bias it was established at the start of the investigation that plants with participation rates below an arbitarily chosen level of $70 \%$ would be excluded. They could however, still be included in subsequent phases of the project. With this criterion, three plants with response rates of $42 \%, 62 \%$, and $64 \%$ were excluded from both the spirometric and symptom analysis. The study population for this phase thus became 1742 employees in 15 plants with an overall response rate of $81 \%$. The participation rate of workers in the $x$ ray film study was lower and a cut off of $60 \%$ was set for inclusion in this part of the study, resulting in an overall response of $74 \%$. Thus the data subsequently analysed concern 1742 questionnaires and 1720 lung function tests from 15 plants and 1096 chest $x$ ray films from 10 plants

The study population was essentially a white male European group with $8 \%$ women and $2 \%$ non-Europeans. The mean age was $41 \cdot 2$ (range 16 to 65) years and variation in mean age between plants was small ( $37 \cdot 4$ to $44 \cdot 2$ years). Mean duration of employment was 14.2 years with a range of plant means from $10 \cdot 3$ to $17 \cdot 7$ years. Nearly half $(48 \%)$ were current cigarette smokers and the rest were evenly divided between never and ex-smokers.

Fourteen per cent of the study subjects had previously been employed in jobs with a well recognised potential respiratory risk-mainly iron and steel foundry work. The removal of asbestos lagging in one plant during the time of employment of the group accounts for $54 \%$ of this plant reporting previous exposure to asbestos.

What information was available on non-responders suggests that they were marginally older than the responders (mean age $44 \cdot 1$ years) and had a somewhat shorter employment period ( 11.8 years).

Table 2 shows the exposure groupings for current and cumulative dust exposure, all except that for current respirable exposure are logarithmically spaced. The geometric mean for inspirable dust for the 15 plants included in the questionnaire and spirometry analysis was 0.57 (geometric standard deviation (GSD) 4.0 ) $\mathrm{mg} \cdot \mathrm{m}^{-3}$ for the three excluded plants $0.50(4.6) \mathrm{mg}^{-3}$, and for respirable dust $0.21(2.7) \mathrm{mg} \cdot \mathrm{m}^{-3}$ and $0.21(3.1)$ $\mathrm{mg} \cdot \mathrm{m}^{-3}$. The geometric mean for inspirable dust for the 10 plants included in the $x$ ray film analysis was 0.55 (4.0) $\mathrm{mg} \cdot \mathrm{m}^{-3}$, for the eight excluded plants,

Table 2 Current and cumulative exposure indices for both respirable and inspirable dust

\begin{tabular}{|c|c|c|c|c|}
\hline \multirow[b]{2}{*}{ Group } & \multicolumn{2}{|c|}{ Current indices } & \multicolumn{2}{|c|}{ Cumulative indices } \\
\hline & $\begin{array}{l}\text { Respirable } \\
\left(m g . m^{-3}\right)\end{array}$ & $\begin{array}{l}\text { Inspirable } \\
\left(\mathrm{mg}^{\left.-m^{-3}\right)}\right.\end{array}$ & $\begin{array}{l}\text { Respirable (mg } \\
\text { months } m^{-3} \text { ) }\end{array}$ & $\begin{array}{l}\text { Inspirable (mg } \\
\text { months } m^{-3}\end{array}$ \\
\hline $\begin{array}{l}1 \\
2 \\
3 \\
4 \\
5\end{array}$ & $\begin{array}{l}0-0.14 \\
0.15-0.19 \\
0.20-0.29 \\
0.30-0.44 \\
>0.45\end{array}$ & $\begin{array}{l}0-0.19 \\
0.20-0.39 \\
0.40-0.79 \\
0.80-1.59 \\
>1.60\end{array}$ & $\begin{array}{l}0-9 \cdot 9 \\
10-19 \cdot 9 \\
20-39 \cdot 9 \\
40-79 \cdot 9 \\
>80\end{array}$ & $\begin{array}{l}0-19 \cdot 9 \\
20-39 \cdot 9 \\
40-79 \cdot 9 \\
80-159 \cdot 9 \\
>160\end{array}$ \\
\hline
\end{tabular}


Table 3 Prevalence of respiratory symptoms by current and cumulative exposure to respirable dust

\begin{tabular}{|c|c|c|c|c|c|c|c|c|c|c|}
\hline \multirow[b]{3}{*}{ Symptom } & \multicolumn{10}{|c|}{ Exposure groups } \\
\hline & \multicolumn{5}{|c|}{ Current } & \multicolumn{5}{|c|}{ Cumulative } \\
\hline & 1 & 2 & 3 & 4 & 5 & 1 & 2 & 3 & 4 & 5 \\
\hline Number & 425 & 407 & 582 & 243 & 85 & 296 & 228 & 484 & 582 & 152 \\
\hline Cough $(\%)$ & 11 & 13 & 18 & 26 & $2 i$ & 9 & 13 & 15 & 20 & 29 \\
\hline Sputum(\%) & 10 & 17 & 20 & 27 & 22 & 11 & 16 & 17 & 22 & 26 \\
\hline Chronic bronchitis(\%) & 6 & 9 & 11 & 15 & 15 & 5 & 7 & 10 & 13 & 14 \\
\hline Sputum without cough(\%) & 4 & 8 & 9 & 9 & 9 & 5 & 9 & 7 & 9 & 9 \\
\hline Wheeze(\%) & 9 & 4 & 13 & 14 & 11 & 6 & 9 & 10 & 12 & 11 \\
\hline Dyspnoea grade $2+(\%)$ & 15 & 14 & 14 & 20 & 18 & 9 & 11 & 16 & 17 & 21 \\
\hline Dyspnoea grade $3+(\%)$ & 4 & 3 & 4 & 9 & 1 & 4 & 3 & 3 & 6 & 7 \\
\hline
\end{tabular}

Table 4 Prevalence of respiratory symptoms by current and cumulative exposure to inspirable dust

\begin{tabular}{|c|c|c|c|c|c|c|c|c|c|c|}
\hline \multirow[b]{3}{*}{ Symptom } & \multicolumn{10}{|c|}{ Exposure groups } \\
\hline & \multicolumn{5}{|c|}{ Current } & \multicolumn{5}{|c|}{ Cumulative } \\
\hline & 1 & 2 & 3 & 4 & 5 & 1 & 2 & 3 & 4 & 5 \\
\hline Number & 223 & 442 & 530 & 380 & 167 & 287 & 197 & 327 & 441 & 490 \\
\hline Cough(\%) & 11 & 11 & 18 & 20 & 26 & 8 & 13 & 15 & 19 & 22 \\
\hline Sputum(\%) & 9 & 12 & 22 & 22 & 26 & 9 & 14 & 17 & 22 & 22 \\
\hline Chronic bronchitis(\%) & 5 & 6 & 12 & 12 & 16 & 5 & 7 & 9 & 14 & 12 \\
\hline Sputum without cough(\%) & 3 & 6 & 10 & 9 & 11 & 4 & 6 & 8 & 10 & 9 \\
\hline Wheeze(\%) & 10 & 6 & 10 & 12 & 13 & 7 & 12 & 7 & 10 & 12 \\
\hline Dyspnoea grade $2+(\%)$ & 17 & 13 & 15 & 16 & 19 & 9 & 14 & 14 & 17 & 17 \\
\hline Dyspnoea grade $3+(\%)$ & 5 & 4 & 3 & 5 & 6 & 3 & 5 & 2 & 6 & 6 \\
\hline
\end{tabular}

$0.57(4.2) \mathrm{mg} \cdot \mathrm{m}^{-3}$ and for respirable dust 0.21 $(2 \cdot 8) \mathrm{mg} \cdot \mathrm{m}^{-3}$ and $0.22(2 \cdot 7) \mathrm{mg} \cdot \mathrm{m}^{-3}$. Therefore, the geometric mean exposure in the plants included is remarkably similar to that in those not included.

\section{QUESTIONNAIRE}

The 1742 questionnaires were, after some rejections and requests for additional data, $99 \%$ complete. Missing questionnaire responses were mostly in the skin disorders section.

The mean prevalence (range from plant to plant) of respiratory symptoms was generally low. Most frequent were cough $17 \%$ ( $8 \%-33 \%$ ), sputum $18 \%$ (9\%-30\%), chronic bronchitis $10 \%(4 \%-16 \%)$, wheeze $10 \%(1 \%-26 \%)$ and dyspnoea grade $2+$ $15 \%(4 \%-31 \%)$. These values were lower than those found by Crosbie ${ }^{13}$ but comparable with other respiratory morbidity studies in European industrial populations with similar mean ages and smoking habits. There was little variation between plants, except that one of three plants had prevalences for either cough, sputum, or dyspnoea grade $2+$ of about $30 \%$. There is no obvious reason for this difference, including geographical considerations. Most symptoms showed a distinct and increasing trend with increasing age, and, among current cigarette smokers, with increasing cigarette consumption.

When the prevalence of symptoms was examined in relation to current and cumulative dust exposure, cough, sputum, and chronic bronchitis it showed clear increasing trends (tables 3 and 4) These effects could, however, be due to confounding effects of age, smoking, or previous hazardous $\odot$ exposure. Therefore a multiple logistic regression model was used to control simultaneously for these possible confounding factors. In this model, the effect of each higher exposure group on any symptom was compared with that of the base or lowest exposure group in turn by estimating the odds ratio for that symptom after adjusting for age, smoking, and previous hazardous exposure. The women, who constituted only $8 \%$ of the study population, were excluded from this analysis. The $p$ values are shown for both current and cumulative and respirable and inspirable dust exposure (table 5).

Table 5 Symptoms and exposure to dust: $p$ values for the differences between exposure groups (respirable and inspirable, current and cumulative) from the multiple logistic regression model

\begin{tabular}{|c|c|c|c|c|}
\hline \multirow[b]{2}{*}{ Symptom } & \multicolumn{2}{|c|}{ Current exposure } & \multicolumn{2}{|c|}{ Cumulative exposure } \\
\hline & Respirable & Inspirable & Respirable & Inspirable \\
\hline Cough & $<0.001$ & $<0.005$ & $<0.05$ & NS \\
\hline Sputum & $<0.005$ & $<0.005$ & NS & NS \\
\hline $\begin{array}{l}\text { Sputum without } \\
\text { cough }\end{array}$ & NS & NS & $\mathbf{N}$ & \\
\hline Chronic bronchitis & $<0.05$ & $<0.005$ & NS & $<0.05$ \\
\hline $\begin{array}{l}\text { Wheeze } \\
\text { Wheeze and }\end{array}$ & $<0.001$ & NS & NS & NS \\
\hline $\begin{array}{l}\text { dyspnoea } \\
\text { Dyspnoea }\end{array}$ & $\begin{array}{l}<0.05 \\
\text { NS }\end{array}$ & $\begin{array}{l}\text { NS } \\
\text { NS }\end{array}$ & $\begin{array}{l}<0.05 \\
\text { NS }\end{array}$ & $\begin{array}{l}<0.05 \\
\text { NS }\end{array}$ \\
\hline
\end{tabular}


There were significant differences between the odds ratios for current indices of respirable dust exposure for the prevalence of cough and wheeze $(\mathrm{p}<0.001)$, symptoms of chronic bronchitis and wheeze and dyspnoea $(p<0.05)$, and sputum $(p<0.005)$, and for inspirable dust exposure with cough, sputum, and the symptoms of chronic bronchitis $(p<0.005)$. For cumulative exposure, only cough and wheeze and dyspnoea $(p<0.05)$ were significant for respirable dust and for inspirable dust only symptoms of chronic bronchitis and wheeze and dyspnoea $(p<0.05)$ were significant. A number of other symptoms showed odds ratios of a consistent trend (especially for current exposure) but the differences in the odds were not significant.

Thus, these results indicate significantly increasing rates for symptoms of cough, sputum, and chronic bronchitis with increasing exposure. The associations with increasing current exposure are greater and more significant than those with increasing cumulative exposure, and the associations seem in general to be greater for respirable exposure than inspirable exposure.

\section{LUNG FUNCTION}

Of the 1720 participants (22 of those who completed a questionnaire did not provide a spirometry trace), satisfactory Vitalograph recordings were obtained from 1575 (91\%). The most common reason for rejecting a trace was the absence of a satisfactory plateau towards the end of the trace.

Table 6 Mean (SD) of the predicted lung function (\%) by current respirable exposure grous and smoking habits

\begin{tabular}{|c|c|c|c|c|c|c|}
\hline \multirow{2}{*}{$\begin{array}{l}\text { Percentage } \\
\text { predicted }\end{array}$} & \multicolumn{5}{|c|}{ Exposure groups } & \multirow[b]{2}{*}{ All } \\
\hline & 1 & 2 & 3 & 4 & 5 & \\
\hline \multicolumn{7}{|c|}{ Never smokers: } \\
\hline $\mathrm{FEV}_{1}$ & $\begin{array}{r}107 \cdot 4 \\
13 \cdot 2\end{array}$ & $\begin{array}{r}108 \cdot 4 \\
11 \cdot 8\end{array}$ & $\begin{array}{r}106 \cdot 5 \\
18 \cdot 8\end{array}$ & $\begin{array}{r}102 \cdot 2 \\
12 \cdot 8\end{array}$ & $\begin{array}{l}99 \cdot 1 \\
10 \cdot 4\end{array}$ & $\begin{array}{r}106.4 \\
14.9\end{array}$ \\
\hline \multirow[t]{2}{*}{ FVC } & $112 \cdot 0$ & $110 \cdot 4$ & $111 \cdot 0$ & $105 \cdot 7$ & $107 \cdot 4$ & $110 \cdot 4$ \\
\hline & $13 \cdot 5$ & $11 \cdot 6$ & $21 \cdot 4$ & $14 \cdot 4$ & $11 \cdot 6$ & $16 \cdot 0$ \\
\hline \multirow{2}{*}{$\mathrm{FEF}_{25-75}$} & $90 \cdot 4$ & $96 \cdot 7$ & $89 \cdot 5$ & $87 \cdot 7$ & $76 \cdot 5$ & $90 \cdot 8$ \\
\hline & $23 \cdot 3$ & $26 \cdot 9$ & $27 \cdot 4$ & $21 \cdot 5$ & $23 \cdot 8$ & $25 \cdot 6$ \\
\hline No & 112 & 95 & 119 & 45 & 15 & 386 \\
\hline \multicolumn{7}{|l|}{ Ex-smokers: } \\
\hline \multirow[t]{2}{*}{$\mathrm{FEV}_{1}$} & $106 \cdot 3$ & $108 \cdot 1$ & $101 \cdot 6$ & $106 \cdot 5$ & $98 \cdot 6$ & $104 \cdot 9$ \\
\hline & $13 \cdot 1$ & $13 \cdot 3$ & $15 \cdot 6$ & $15 \cdot 0$ & $17 \cdot 1$ & $14 \cdot 6$ \\
\hline \multirow[t]{2}{*}{ FVC } & $110 \cdot 2$ & $112 \cdot 0$ & $108 \cdot 8$ & $114 \cdot 3$ & $109 \cdot 7$ & $110 \cdot 6$ \\
\hline & $12 \cdot 5$ & $13 \cdot 1$ & $13 \cdot 3$ & $15 \cdot 5$ & $16 \cdot 1$ & 13.4 \\
\hline \multirow[t]{2}{*}{$\mathrm{FEF}_{25-75}$} & $90 \cdot 1$ & $91 \cdot 8$ & $77 \cdot 9$ & $84 \cdot 6$ & $69 \cdot 5$ & $85 \cdot 0$ \\
\hline & $27 \cdot 3$ & $26 \cdot 2$ & $27 \cdot 7$ & $30 \cdot 3$ & $28 \cdot 3$ & $28 \cdot 2$ \\
\hline No & 121 & 106 & 153 & 46 & 16 & 442 \\
\hline \multicolumn{7}{|c|}{ Current smokers: } \\
\hline \multirow[t]{2}{*}{$\mathrm{FEV}_{1}$} & $102 \cdot 1$ & $103 \cdot 6$ & $101 \cdot 5$ & $98 \cdot 6$ & $98 \cdot 5$ & $101 \cdot 4$ \\
\hline & $14 \cdot 2$ & $11 \cdot 6$ & $14 \cdot 2$ & $26 \cdot 5$ & $13 \cdot 4$ & $16 \cdot 5$ \\
\hline \multirow[t]{2}{*}{ FVC } & $109 \cdot 2$ & $108 \cdot 2$ & $109 \cdot 7$ & $108 \cdot 1$ & $105 \cdot 6$ & $108 \cdot 7$ \\
\hline & $14 \cdot 1$ & $11 \cdot 7$ & $13 \cdot 4$ & $38 \cdot 0$ & $15 \cdot 2$ & $19 \cdot 8$ \\
\hline \multirow[t]{2}{*}{$\mathrm{FEF}_{25-75}$} & $81 \cdot 7$ & $86 \cdot 7$ & $77 \cdot 8$ & $73 \cdot 3$ & $78 \cdot 2$ & $79 \cdot 8$ \\
\hline & $28 \cdot 3$ & $25 \cdot 1$ & $26 \cdot 8$ & $24 \cdot 5$ & $25 \cdot 0$ & $26 \cdot 6$ \\
\hline No & 148 & 168 & 256 & 127 & 48 & 747 \\
\hline Total No & 381 & 369 & 528 & 218 & 79 & 1575 \\
\hline
\end{tabular}

Initial comparison of lung function indices of $\mathrm{FEV}_{1}, \mathrm{FVC}$, and $\mathrm{FEF}_{25-75}$ were made from calculating percentage predicted values from the ECCS reference values, ${ }^{30}$ these do not include a standardisation for smoking.

The ratio of observed to predicted values was, in general, high although the typical effects of smoking were seen on all percentage predicted values, especially for $\mathrm{FEF}_{25-75}$. These values stratified by smoking category were then examined in relation to the exposure groups for current and cumulative respirable and inspirable dust (tables 6-9).

Never smokers showed an overall decrease in lung function with increasing exposure (more noticeable for current respirable and inspirable exposure than for the cumulative indices) although the fall was not consistent between all exposure groups. Smaller decreases in lung function were also seen in both ex and current smokers in relation to both current and cumulative exposure. These effects were more evident for $\mathrm{FEV}_{1}$ and $\mathrm{FEF}_{25-75}$ than for FVC. They were, however, comparable in size to the apparent effects of smoking.

The relation between these effects and exposure to carbon black was further examined with the multiple linear regression analysis. The effect of exposure was estimated while simultaneously controlling for possible confounding effects such as age, smoking, and previous respiratory hazard exposures as for the symptom analysis. Also height was included and non-Europeans and women were excluded. Terms for each exposure category (as in

Table 7 Mean (SD) of the predicted lung function (\%) by current inspirable exposure group and smoking habits

\begin{tabular}{|c|c|c|c|c|c|c|}
\hline \multirow{2}{*}{$\begin{array}{l}\text { Percentage } \\
\text { predicted }\end{array}$} & \multicolumn{5}{|c|}{ Exposure groups } & \multirow[b]{2}{*}{ All } \\
\hline & 1 & 2 & 3 & 4 & 5 & \\
\hline \multicolumn{7}{|c|}{ Never smokers: } \\
\hline \multirow[t]{2}{*}{ FEV } & $109 \cdot 2$ & $105 \cdot 8$ & $107 \cdot 9$ & $106 \cdot 2$ & $98 \cdot 8$ & $106 \cdot 4$ \\
\hline & $13 \cdot 6$ & $12 \cdot 3$ & $19 \cdot 2$ & $11 \cdot 3$ & $12 \cdot 8$ & $14 \cdot 9$ \\
\hline \multirow[t]{2}{*}{ FVC } & $113 \cdot 1$ & $110 \cdot 1$ & $111 \cdot 3$ & $109 \cdot 4$ & $105 \cdot 5$ & $110 \cdot 4$ \\
\hline & $14 \cdot 2$ & $12 \cdot 4$ & $22 \cdot 0$ & $11 \cdot 2$ & $15 \cdot 4$ & $16 \cdot 0$ \\
\hline \multirow[t]{2}{*}{$\mathrm{FEF}_{25-75}$} & $92 \cdot 0$ & $89 \cdot 8$ & $93 \cdot 1$ & $92 \cdot 8$ & $80 \cdot 2$ & $90 \cdot 8$ \\
\hline & $20 \cdot 4$ & $26 \cdot 1$ & $26 \cdot 5$ & $28 \cdot 1$ & $22 \cdot 6$ & $25 \cdot 6$ \\
\hline No & 60 & 115 & 110 & 69 & 32 & 386 \\
\hline \multicolumn{7}{|l|}{ Ex-smokers: } \\
\hline \multirow[t]{2}{*}{$\mathrm{FEV}_{1}$} & $105 \cdot 2$ & $107 \cdot 0$ & $105 \cdot 3$ & $102 \cdot 0$ & $102 \cdot 9$ & $104 \cdot 9$ \\
\hline & $14 \cdot 1$ & $13 \cdot 6$ & $14 \cdot 6$ & $16 \cdot 1$ & $14 \cdot 2$ & $14 \cdot 6$ \\
\hline \multirow[t]{2}{*}{ FVC } & $109 \cdot 9$ & $110 \cdot 7$ & $111 \cdot 6$ & $109 \cdot 4$ & $111 \cdot 1$ & $110 \cdot 6$ \\
\hline & $12 \cdot 4$ & $13 \cdot 7$ & $13 \cdot 0$ & $14 \cdot 4$ & $14 \cdot 2$ & $13 \cdot 4$ \\
\hline \multirow[t]{2}{*}{$\mathrm{FEF}_{25-75}$} & $87 \cdot 9$ & $91 \cdot 7$ & $82 \cdot 7$ & $80 \cdot 1$ & $77 \cdot 1$ & $85 \cdot 0$ \\
\hline & $28 \cdot 9$ & $26 \cdot 4$ & $26 \cdot 7$ & $31 \cdot 1$ & $24 \cdot 7$ & $28 \cdot 2$ \\
\hline No & 73 & 116 & 127 & 96 & 30 & 442 \\
\hline \multicolumn{7}{|c|}{ Current smokers: } \\
\hline \multirow[t]{2}{*}{$\mathrm{FEV}_{1}$} & $101 \cdot 5$ & $102 \cdot 7$ & $103 \cdot 0$ & $99 \cdot 4$ & $98 \cdot 3$ & $101 \cdot 4$ \\
\hline & $14 \cdot 8$ & $12 \cdot 7$ & $13 \cdot 6$ & 23.6 & $13 \cdot 1$ & $16 \cdot 5$ \\
\hline \multirow[t]{2}{*}{ FVC } & $108 \cdot 1$ & $109 \cdot 3$ & $109 \cdot 9$ & $108 \cdot 7$ & $104 \cdot 9$ & $108 \cdot 7$ \\
\hline & $13 \cdot 2$ & $13 \cdot 0$ & $12 \cdot 7$ & $33 \cdot 2$ & $13 \cdot 4$ & $19 \cdot 8$ \\
\hline \multirow[t]{2}{*}{$\mathrm{FEF}_{2575}$} & $82 \cdot 0$ & $82 \cdot 7$ & $82 \cdot 1$ & $73 \cdot 8$ & $78 \cdot 5$ & $79 \cdot 8$ \\
\hline & $28 \cdot 6$ & $26 \cdot 8$ & $26 \cdot 9$ & $25 \cdot 8$ & $23 \cdot 2$ & $26 \cdot 6$ \\
\hline No & 70 & 167 & 243 & 178 & 89 & 747 \\
\hline Total No & 203 & 398 & 480 & 343 & 151 & 1575 \\
\hline
\end{tabular}


Table 8 Mean (SD) of the predicted lung function (\%) by cumulative respirable exposure group and smoking habits

\begin{tabular}{|c|c|c|c|c|c|c|}
\hline \multirow{2}{*}{$\begin{array}{l}\text { Percentage } \\
\text { predicted }\end{array}$} & \multicolumn{5}{|c|}{ Exposure groups } & \multirow[b]{2}{*}{ All } \\
\hline & 1 & 2 & 3 & 4 & 5 & \\
\hline \multicolumn{7}{|c|}{ Never smokers: } \\
\hline FEV $_{1}$ & $\begin{array}{r}107 \cdot 1 \\
18 \cdot 2\end{array}$ & $\begin{array}{r}104.5 \\
11.5\end{array}$ & $\begin{array}{r}108 \cdot 3 \\
13 \cdot 3\end{array}$ & $\begin{array}{r}104 \cdot 8 \\
14 \cdot 5\end{array}$ & $\begin{array}{r}106 \cdot 8 \\
13 \cdot 0\end{array}$ & $\begin{array}{r}106.4 \\
14.9\end{array}$ \\
\hline \multirow[t]{2}{*}{ FVC } & $110 \cdot 2$ & $108 \cdot 7$ & 112.7 & $108 \cdot 8$ & $111 \cdot 8$ & 110.4 \\
\hline & $21 \cdot 8$ & $12 \cdot 7$ & $13 \cdot 3$ & $13 \cdot 8$ & $11 \cdot 7$ & 16.0 \\
\hline \multirow{2}{*}{$\mathrm{FEF}_{25-75}$} & 93.9 & $89 \cdot 0$ & $91 \cdot 3$ & $88 \cdot 6$ & $89 \cdot 1$ & $90 \cdot 8$ \\
\hline & $23 \cdot 8$ & $23 \cdot 2$ & $24 \cdot 1$ & $29 \cdot 8$ & $27 \cdot 2$ & $25 \cdot 6$ \\
\hline No & 105 & 58 & 101 & 97 & 25 & 386 \\
\hline \multicolumn{7}{|c|}{ Ex-smokers: } \\
\hline $\mathrm{FEV}_{1}$ & $107 \cdot 3$ & $106 \cdot 4$ & $106 \cdot 8$ & $103 \cdot 7$ & $98 \cdot 5$ & $104 \cdot 9$ \\
\hline \multirow{2}{*}{ FVC } & $\begin{array}{r}13 \cdot 3 \\
110 \cdot 4\end{array}$ & $\begin{array}{r}13 \cdot 6 \\
110.5\end{array}$ & $\begin{array}{r}12 \cdot 6 \\
112 \cdot 2\end{array}$ & $\begin{array}{r}16 \cdot 6 \\
110.7\end{array}$ & $\begin{array}{r}13 \cdot 0 \\
105 \cdot 6\end{array}$ & $\begin{array}{l}14 \cdot 6 \\
110 \cdot 6\end{array}$ \\
\hline & $15 \cdot 4$ & 12.9 & 11.5 & 14.0 & 13.4 & 13.4 \\
\hline \multirow[t]{3}{*}{$\mathrm{FEF}_{25-75}$} & $97 \cdot 7$ & $91 \cdot 3$ & $86 \cdot 6$ & $80 \cdot 4$ & $73 \cdot 4$ & $85 \cdot 0$ \\
\hline & $28 \cdot 3$ & $27 \cdot 1$ & $26 \cdot 1$ & $28 \cdot 8$ & $25 \cdot 1$ & $28 \cdot 2$ \\
\hline & 57 & 52 & 123 & 169 & 41 & 442 \\
\hline \multicolumn{7}{|c|}{ Current smokers: } \\
\hline \multirow[t]{2}{*}{$\mathrm{FEV}_{1}$} & $102 \cdot 0$ & $105 \cdot 5$ & $101 \cdot 0$ & $100 \cdot 2$ & $99 \cdot 8$ & 101.4 \\
\hline & $11 \cdot 1$ & 13.6 & $14 \cdot 0$ & $13 \cdot 2$ & $34 \cdot 9$ & $16 \cdot 5$ \\
\hline \multirow[t]{2}{*}{ FVC } & $106 \cdot 2$ & $111 \cdot 2$ & 107.9 & $108 \cdot 8$ & 111.7 & $108 \cdot 7$ \\
\hline & $12 \cdot 2$ & $13 \cdot 2$ & 13.4 & $12 \cdot 5$ & $50 \cdot 8$ & $19 \cdot 8$ \\
\hline \multirow{2}{*}{$\mathrm{FEF}_{25-75}$} & $87 \cdot 0$ & $87 \cdot 7$ & $81 \cdot 6$ & $74 \cdot 6$ & $69 \cdot 5$ & $79 \cdot 8$ \\
\hline & $20 \cdot 4$ & $27 \cdot 3$ & $\begin{array}{r}29 \cdot 1 \\
217\end{array}$ & $25 \cdot 0$ & $24 \cdot 8$ & $26 \cdot 6$ \\
\hline Total & An & 20 & & & & 141 \\
\hline Total & 277 & 212 & 441 & 509 & 136 & 1575 \\
\hline
\end{tabular}

table 2) above the lowest (that is for groups 2-5) were included as discrete variables thus giving actual estimates of change in lung function (l) associated with each group above the lowest after adjusting for confounding factors. This analysis avoids the assumption of equal changes in lung function between people in successive exposure categories.

The results are given for the 1389 male white Europeans (table 10) for current and cumulative respirable dust. For never smokers there were significant and increasing effects on $\mathrm{FEV}_{1}$ and $\mathrm{FEF}_{25-75}$ with current exposure and similar but more significant effects for ex and current smokers. For cumulative exposure, less consistent results were evident and the only statistically significant result is for FEF (25\%-75\%) for ex-smokers.

These results suggest a respiratory effect related more to current exposure than cumulative, as seen in the symptom analysis.

\section{RADIOGRAPHIC CHANGES}

Chest radiographs were available for 1658 (54\%) of the study population. As described earlier, the analysis was restricted to those 10 plants with response rates in excess of $60 \%$. This reduced the number to 1096 radiographs (response rate $73.9 \%$ ). Film quality was defined by the ILO 1980 classification ${ }^{24}$; the median film quality reading was good for $20 \%$ of the films, acceptable for $52 \%$, and poor for $27 \%$. Six films were unreadable. A further six people did not complete the questionnaire, and
Table 9 Mean (SD) of the predicted lung function (\%) by cumulative inspirable exposure group and smoking habits

\begin{tabular}{|c|c|c|c|c|c|c|}
\hline \multirow{2}{*}{$\begin{array}{l}\text { Percentage } \\
\text { predicted }\end{array}$} & \multicolumn{5}{|c|}{ Exposure groups } & \multirow[b]{2}{*}{ All } \\
\hline & 1 & 2 & 3 & 4 & 5 & \\
\hline \multicolumn{7}{|c|}{ Never smokers: } \\
\hline $\mathrm{FEV}_{1}$ & $\begin{array}{r}107 \cdot 9 \\
18.3\end{array}$ & $\begin{array}{r}107 \cdot 4 \\
11 \cdot 8\end{array}$ & $\begin{array}{r}105 \cdot 6 \\
12 \cdot 3\end{array}$ & $\begin{array}{r}105.9 \\
14.7\end{array}$ & $\begin{array}{r}104.9 \\
13.7\end{array}$ & $\begin{array}{r}106 \cdot 4 \\
14.9\end{array}$ \\
\hline FVC & $110 \cdot 8$ & $112 \cdot 6$ & $110 \cdot 1$ & $110 \cdot 0$ & $108 \cdot 9$ & $110 \cdot 4$ \\
\hline & $21 \cdot 7$ & $13 \cdot 7$ & $12 \cdot 1$ & $14 \cdot 6$ & $12 \cdot 8$ & $16 \cdot 0$ \\
\hline $\mathrm{FEF}_{25-75}$ & $94 \cdot 5$ & $89 \cdot 3$ & $90 \cdot 0$ & $88 \cdot 4$ & $90 \cdot 1$ & $90 \cdot 8$ \\
\hline & $23 \cdot 9$ & $21 \cdot 1$ & $27 \cdot 5$ & $24 \cdot 7$ & $29 \cdot 6$ & $25 \cdot 6$ \\
\hline No & 106 & 54 & 64 & 80 & 82 & 386 \\
\hline \multicolumn{7}{|c|}{ Ex-smokers: } \\
\hline $\mathrm{FEV}_{1}$ & $107 \cdot 1$ & $106 \cdot 1$ & $107 \cdot 1$ & $106 \cdot 7$ & $100 \cdot 5$ & $104 \cdot 9$ \\
\hline & $13 \cdot 6$ & $11 \cdot 8$ & $14 \cdot 6$ & $13 \cdot 9$ & $15 \cdot 9$ & $14 \cdot 6$ \\
\hline FVC & $109 \cdot 5$ & $110 \cdot 8$ & $113 \cdot 2$ & $111 \cdot 7$ & $108 \cdot 7$ & $110 \cdot 6$ \\
\hline & $13 \cdot 5$ & $13 \cdot 8$ & $13 \cdot 3$ & $12 \cdot 6$ & $14 \cdot 0$ & $13 \cdot 4$ \\
\hline $\mathrm{FEF}_{25-75}$ & $95 \cdot 3$ & $91 \cdot 6$ & $86 \cdot 6$ & $87 \cdot 9$ & $74 \cdot 4$ & $85 \cdot 0$ \\
\hline & $24 \cdot 7$ & $29 \cdot 8$ & $28 \cdot 8$ & $27 \cdot 9$ & $26 \cdot 1$ & $28 \cdot 2$ \\
\hline No & 62 & 52 & 72 & 120 & 136 & 442 \\
\hline \multicolumn{7}{|c|}{ Current smokers: } \\
\hline $\mathrm{FEV}_{1}$ & $\begin{array}{r}103 \cdot 3 \\
12 \cdot 1\end{array}$ & $\begin{array}{r}103.6 \\
13.5\end{array}$ & $\begin{array}{r}102 \cdot 7 \\
14 \cdot 2\end{array}$ & $\begin{array}{r}100 \cdot 8 \\
13.4\end{array}$ & $\begin{array}{l}99 \cdot 4 \\
22 \cdot 1\end{array}$ & $\begin{array}{r}101.4 \\
16.5\end{array}$ \\
\hline FVC & $107 \cdot 7$ & $109 \cdot 6$ & $108 \cdot 7$ & $108 \cdot 3$ & $109 \cdot 2$ & $108 \cdot 7$ \\
\hline & $13 \cdot 2$ & $12 \cdot 2$ & $13 \cdot 4$ & $13 \cdot 3$ & $30 \cdot 4$ & $19 \cdot 8$ \\
\hline $\mathrm{FEF}_{25.75}$ & $87 \cdot 6$ & $85 \cdot 4$ & $86 \cdot 0$ & $78 \cdot 0$ & $71 \cdot 5$ & $79 \cdot 8$ \\
\hline & $20 \cdot 4$ & $29 \cdot 8$ & $29 \cdot 1$ & $26 \cdot 1$ & $23 \cdot 8$ & $26 \cdot 6$ \\
\hline No & 100 & 78 & 154 & 196 & 219 & 747 \\
\hline Total & 268 & 184 & 290 & 396 & 437 & 1575 \\
\hline
\end{tabular}

so the statistical analyses were limited to 1084 people, 1005 men and 79 women.

In the complete series 2071 films were read,

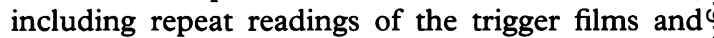
262 films from a different group of workers, some of whom had been exposed to asbestos. There were 42 films that were read by one or more readers as quality 4 (unacceptable). Figure 1 shows the cumulative frequency distributions of readings of small opacities for the remaining 2029 films.

The boundaries between the minor categories have been set so that the combined cumulative frequency distribution is linear. Category $1 / 1$ is wider than categories $0 / 1$ and $1 / 0$, as usually occurs. This reflects the greater proportion of films generally placed in the central minor categories $(0 / 0,1 / 1 \mathrm{etc})$ than in the border categories $(0 / 1,1 / 0$ etc).

Readers 1 and 2 were in reasonable agreement about the distribution of profusion of small opacities. Reader 3, however, read rather more films in category $0 / 1$, with fewer in $0 / 0$ and in the higher minor categories. The effect of this on the median film readings was small. When only two of the three readers agreed that the profusion was category $0 / 0$, reader 3 was least often the odd reader out. He was also least often the single reader who read category $0 / 0$, when two readers agreed that the profusion was higher.

Median readings from the three readers were analysed against exposure groupings as well as against plant, age, and duration of employment in the industry. 
Table 10 Regression coefficients RC (SE) for current and cumulative respirable exposure groups (EG) and $p$ values for differences between them for lung function in smokers and non-smokers separately

\begin{tabular}{|c|c|c|c|c|}
\hline & $E G$ & $\begin{array}{l}\text { Never smoked } \\
R C(S E)\end{array}$ & $\begin{array}{l}\text { Ex-smokers } \\
R C(S E)\end{array}$ & $\begin{array}{l}\text { Current smokers } \\
R C(S E)\end{array}$ \\
\hline $\begin{array}{l}\mathrm{FEV}_{1}: \\
\quad \text { Current respirable }\end{array}$ & $\begin{array}{l}2 \\
3 \\
4 \\
5 \\
\text { p value }\end{array}$ & $\begin{aligned} 0.013(0.079) \\
-0.068(0.073) \\
-0.204(0.096) \\
-0.348(0.149) \\
<0.05\end{aligned}$ & $\begin{aligned} 0.051(0.076) \\
-0.183(0.072) \\
-0.009(0.096) \\
-0.364(0.145) \\
<0.01\end{aligned}$ & $\begin{array}{l}0.064(0.065) \\
-0.021(0.060) \\
-0.149(0.068) \\
-0.125(0.090) \\
<0.01\end{array}$ \\
\hline Cumulative respirable & $\begin{array}{l}2 \\
3 \\
4 \\
5 \\
\mathrm{p} \text { value }\end{array}$ & $\begin{array}{r}-0.027(0.093) \\
0.037(0.087) \\
-0.065(0.099) \\
0.026(0.133) \\
\text { NS }\end{array}$ & $\begin{array}{l}-0.037(0.113) \\
0.001(0.094) \\
-0.041(0.095) \\
-0.164(0.122) \\
\text { NS }\end{array}$ & $\begin{array}{l}0.160(0.077) \\
0.010(0.068) \\
0.020(0.072) \\
-0.060(0.091) \\
\text { NS }\end{array}$ \\
\hline $\begin{array}{l}\text { FVC: } \\
\text { Current respirable }\end{array}$ & $\begin{array}{l}2 \\
3 \\
4 \\
5 \\
\text { p value }\end{array}$ & $\begin{array}{l}-0.079(0.097) \\
-0.066(0.090) \\
-0.267(0.119) \\
-0.129(0.184) \\
\text { NS }\end{array}$ & $\begin{array}{l}0.102(0.089) \\
-0.018(0.085) \\
0.226(0.114) \\
-0.093(0.171) \\
\text { NS }\end{array}$ & $\begin{array}{l}0.031(0.080) \\
0.101(0.074) \\
-0.036(0.084) \\
-0.116(0.111) \\
\text { NS }\end{array}$ \\
\hline Cumulative respirable & $\begin{array}{l}2 \\
3 \\
4 \\
5 \\
\text { p value }\end{array}$ & $\begin{array}{l}0.056(0.114) \\
0.132(0.106) \\
-0.022(0.121) \\
0.088(0.162) \\
\text { NS }\end{array}$ & $\begin{array}{l}-0.018(0.131) \\
0.148(0.109) \\
0.148(0.110) \\
0.002(0.141) \\
\text { NS }\end{array}$ & $\begin{array}{l}0.246(0.094) \\
0.063(0.084) \\
0.149(0.088) \\
0.089(0.111) \\
\text { NS }\end{array}$ \\
\hline $\begin{array}{l}\mathrm{FEF}_{25-75}: \\
\quad \text { Current respirable }\end{array}$ & $\begin{array}{l}2 \\
3 \\
4 \\
5 \\
\text { p value }\end{array}$ & $\begin{aligned} & 0.221(0.178) \\
&-0.115(0.165) \\
&-0.184(0.217) \\
&-0.790(0.337) \\
&<0.05\end{aligned}$ & $\begin{array}{l}-0.045(0.162) \\
-0.586(0.153) \\
-0.299(0.206) \\
-0.951(0.311) \\
<0.001\end{array}$ & $\begin{array}{l}0.120(0.137) \\
-0.268(0.127) \\
-0.431(0.144) \\
-0.153(0.190) \\
<0.01\end{array}$ \\
\hline Cumulative respirable & $\begin{array}{l}2 \\
3 \\
4 \\
5 \\
\text { p Value }\end{array}$ & $\begin{array}{l}-0.117(0.212) \\
-0.132(0.196) \\
-0.153(0.225) \\
-0.158(0.300) \\
\text { NS }\end{array}$ & $\begin{array}{l}-0.292(0.240) \\
-0.527(0.201) \\
-0.617(0.203) \\
-0.753(0.260) \\
<0.05\end{array}$ & $\begin{array}{l}0.121(0.164) \\
0.059(0.145) \\
-0.129(0.153) \\
-0.220(0.193) \\
\text { NS }\end{array}$ \\
\hline
\end{tabular}

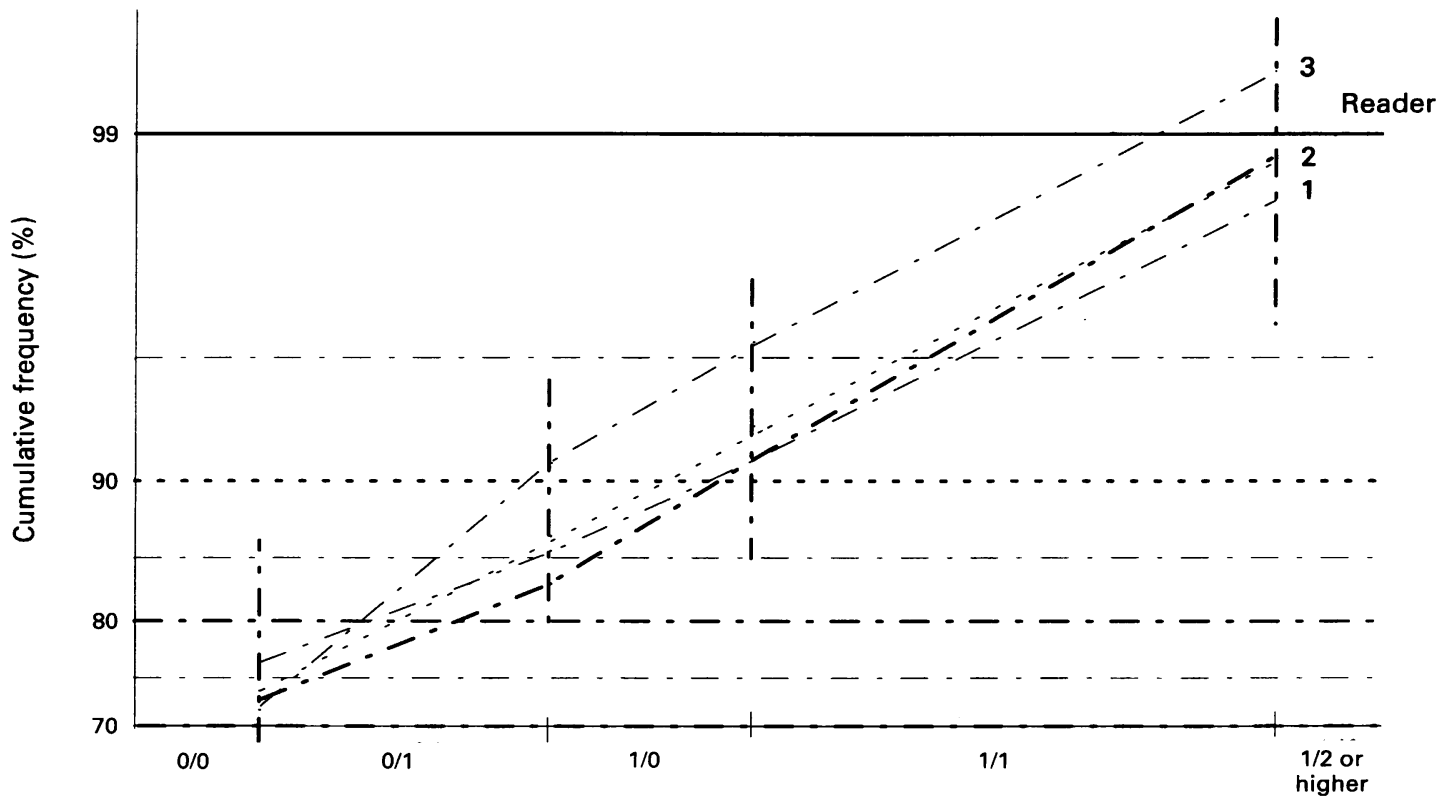

Small opacity profusion

Figure 1 Cumulative frequency distributions: comparison between the three readers. 
Table 11 Tabulation (number of films (\%)) of profusion of small opacities by plant

\begin{tabular}{|c|c|c|c|c|c|c|c|}
\hline Plant & $0 / 0$ & $0 / 1$ & $1 / 0$ & $1 / 1$ & $2 / 1$ & $2 / 2$ & Total \\
\hline $\begin{array}{r}1 \\
2 \\
3 \\
4 \\
6 \\
13 \\
14 \\
15 \\
16 \\
18\end{array}$ & $\begin{array}{r}113(89 \cdot 7) \\
138(92 \cdot 0) \\
77(72 \cdot 0) \\
87(82 \cdot 9) \\
113(64 \cdot 2) \\
73(68 \cdot 9) \\
58(72 \cdot 5) \\
58(65 \cdot 2) \\
54(58 \cdot 1) \\
49(94 \cdot 2)\end{array}$ & $\begin{array}{c}9(7 \cdot 1) \\
10(6 \cdot 7) \\
18(16 \cdot 8) \\
13(12 \cdot 4) \\
28(15 \cdot 9) \\
20(18 \cdot 9) \\
15(18 \cdot 7) \\
18(20 \cdot 2) \\
24(25 \cdot 8) \\
2(3 \cdot 8)\end{array}$ & $\begin{array}{c}3(2 \cdot 4) \\
2(1.3) \\
6(5 \cdot 6) \\
1(1.0) \\
13(7 \cdot 4) \\
9(8.5) \\
5(6.3) \\
6(6.7) \\
10(10.8) \\
1(1.9)\end{array}$ & $\begin{array}{c}1(0 \cdot 8) \\
0(0 \cdot 0) \\
5(4 \cdot 7) \\
3(2 \cdot 9) \\
22(12 \cdot 5) \\
4(3 \cdot 8) \\
2(2 \cdot 5) \\
7(7 \cdot 9) \\
4(4 \cdot 3) \\
0(0 \cdot 0)\end{array}$ & $\begin{array}{l}0(0 \cdot 0) \\
0(0 \cdot 0) \\
1(0.9) \\
0(0.0) \\
0(0.0) \\
0(0.0) \\
0(0.0) \\
0(0.0) \\
1(1 \cdot 1) \\
0(0.0)\end{array}$ & $\begin{array}{l}0(0.0) \\
0(0 \cdot 0) \\
0(0 \cdot 0) \\
1(1 \cdot 0) \\
0(0 \cdot 0) \\
0(0 \cdot 0) \\
0(0 \cdot 0) \\
0(0 \cdot 0) \\
0(0 \cdot 0) \\
0(0 \cdot 0)\end{array}$ & $\begin{array}{r}126 \\
150 \\
107 \\
105 \\
176 \\
106 \\
80 \\
89 \\
93 \\
52\end{array}$ \\
\hline Total & $820(75 \cdot 6)$ & $157(14 \cdot 5)$ & $56(5 \cdot 2)$ & $48(4 \cdot 4)$ & $2(0 \cdot 2)$ & $1(0 \cdot 1)$ & 1084 \\
\hline
\end{tabular}

Table 11 gives the prevalences of the profusion of small opacities for each of the 10 plants. Overall, there were $264(24 \cdot 4 \%)$ people with small opacities of category $0 / 1$ or more, and $107(9.9 \%)$ with opacities of $1 / 0$ or more. The prevalence varied considerably between plants $\chi^{2}=131.09$ with 45 degrees of freedom, $\mathrm{p} \ll 0.001)$ but was unrelated to age $\left(\chi^{2}=19 \cdot 7\right.$ with 20 degrees of freedom, NS) or duration of carbon black employment $\left(\chi^{2}=29.5\right.$ with 25 degrees of freedom, NS). The profusion was significantly associated with both cumulative cigarette consumption and current smoking habit $\left(\chi^{2}=45.8\right.$ with 25 degrees of freedom, $\left.p=0 \cdot 007\right)$. The proportions of people with category $1 / 0$ or more were: non-smokers $4.2 \%$; ex-smokers $11.7 \%$; light cigarette smokers $8.9 \%$; moderate cigarette smokers $14.0 \%$; and heavy cigarette smokers $20.8 \%$. None of the 11 men who smoked only pipes or cigars were identified as showing any small opacities.

The profusion of small opacities also correlated with all four exposure indices (current and cumulative for inspirable and respirable dust) and to job category. The strongest association was with current respirable dust exposure. There were, however, appreciable differences between the exposure indices from plant to plant and also significant associations between smoking habits and the exposure indices.
Surprisingly, profusion was unrelated to previous exposure to asbestos. Of the 94 people who reported previous exposure to asbestos, the prevalence of profusion $1 / 0$ or more was $7 \cdot 4 \%$, compared with $10 \cdot 1 \%$ of the remainder.

The questionnaire data provided information on other possible previous potentially dusty jobs. For some of these, the prevalence of small opacities of category $1 / 0$ or more was significantly raised: prior coal or ore mining $26.2 \%$ (42 people total); prior iron or steel foundry work $19.6 \%$ (46 people); prior farming work $18.6 \%$ (107 people).

There was no reading of a large opacity for any film. Pleural changes were noted in only 11 films and in a further eight obliteration of the costophrenic angle was recorded. Table 12 gives a summary of data for those with pleural changes. Seven of the 11 had reported other dust exposures in response to the questionnaire, and for another the pleural changes were probably not pneumoconiotic.

As noted, the exposure indices varied significantly from plant to plant and they also correlated with smoking habits. Logistic regression analyses were undertaken to relate prevalence of small opacities to the exposure indices to standardise for between plant differences and smoking habits.

The women generally had lower values for the exposure indices than did the men. They also

Table 12 Workers with pleural thickening or calcification

\begin{tabular}{|c|c|c|c|c|}
\hline Age group (y) & $\begin{array}{l}\text { Duration of } \\
\text { Employment }(y)\end{array}$ & Pleural changes & $\begin{array}{l}\text { Small } \\
\text { opacities }\end{array}$ & Comments \\
\hline $\begin{array}{l}45-54 \\
55-64 \\
55-64 \\
35-44\end{array}$ & $\begin{array}{l}20-24 \\
20-24 \\
20-24 \\
20-24\end{array}$ & $\begin{array}{l}\text { Bilateral diffuse, bilateral CPA* } \\
\text { Bilateral calcification } \\
\text { Unilateral diffuse, bilateral CPA } \\
\text { Unilateral diffuse, unilateral CPA }\end{array}$ & $\begin{array}{l}0 / 0 \\
0 / 0 \\
1 / 1 \mathrm{q} / \mathrm{t} \\
0 / 0\end{array}$ & $\begin{array}{l}\text { Farming ( } 12 \text { y) } \\
\text { Exposed to asbestos } \\
\text { Exposed to asbestos } \\
2 \text { y refractory bricks }\end{array}$ \\
\hline $55-64$ & $25-29$ & $\begin{array}{l}\text { Unilateral diffuse, unilateral calcification, } \\
\text { unilateral CPA }\end{array}$ & $0 / 0$ & $\begin{array}{l}\text { Recorded as 'other } \\
\text { disease' by } x \text { ray film readers }\end{array}$ \\
\hline $\begin{array}{l}45-54 \\
45-54 \\
45-54 \\
55-64 \\
55-64 \\
45-54\end{array}$ & $\begin{array}{l}25-29 \\
25-29 \\
25-29 \\
20-24 \\
15-19 \\
25-29\end{array}$ & $\begin{array}{l}\text { Unilateral circumscribed, unilateral calcification } \\
\text { Unilateral diffuse, unilateral CPA } \\
\text { Unilateral diffuse } \\
\text { Unilateral diffuse } \\
\text { Unilateral calcification } \\
\text { Unilateral calcification }\end{array}$ & $\begin{array}{l}0 / 0 \\
0 / 0 \\
0 / 1 \mathrm{q} / \mathrm{q} \\
0 / 0 \\
0 / 0 \\
1 / 1 \mathrm{t} / \mathrm{t}\end{array}$ & $\begin{array}{l}\text { Exposed to asbestos } \\
\text { Pottery }(17 \mathrm{y}) \\
\text { Asbestos }(15 \mathrm{y}) \\
\text { Farming }(4 \mathrm{y})\end{array}$ \\
\hline
\end{tabular}

${ }^{\star} \mathrm{CPA}=$ Costophrenic angle obliteration. 
Table 13 Logistic regression of profusion of small opacities deviances (D) and $p$ values

\begin{tabular}{|c|c|c|c|c|c|c|c|c|c|c|c|c|}
\hline & \multicolumn{2}{|l|}{ Independent variables } & \multicolumn{10}{|c|}{ Dependent variables: profusion of small opacities } \\
\hline & \multirow[b]{2}{*}{ Groups } & \multirow{2}{*}{$\begin{array}{l}\text { Degrees } \\
\text { of } \\
\text { freedom }\end{array}$} & \multicolumn{2}{|c|}{$\begin{array}{l}\text { All opacities } \\
0 / 1 \text { or greater }\end{array}$} & \multicolumn{2}{|c|}{$\begin{array}{l}\text { All opacities } \\
1 / 0 \text { or greater }\end{array}$} & \multicolumn{2}{|c|}{$\begin{array}{l}\text { All opacities } \\
1 / 1 \text { or greater }\end{array}$} & \multicolumn{2}{|c|}{$\begin{array}{l}\text { Rounded } 1 / 0 \\
\text { or greater }\end{array}$} & \multicolumn{2}{|c|}{$\begin{array}{l}\text { Irregular } 1 / 0 \\
\text { or greater }\end{array}$} \\
\hline & & & $D$ & p Value & $D$ & p Value & $D$ & p Value & $D$ & p Value & $D$ & p Value \\
\hline \multirow[t]{4}{*}{$\begin{array}{l}\text { Terms included } \\
\text { in best fit model }\end{array}$} & $\begin{array}{l}\text { Plant } \\
\text { Current smok }\end{array}$ & $\begin{array}{l}9 \\
5\end{array}$ & $\begin{array}{l}81 \cdot 1 \\
19 \cdot 2\end{array}$ & $\begin{array}{c}<0.0001 \\
0.002\end{array}$ & $\begin{array}{l}52 \cdot 1 \\
22 \cdot 0\end{array}$ & $\begin{array}{l}<0.001 \\
<0.001\end{array}$ & $\begin{array}{l}44 \cdot 3 \\
11 \cdot 2\end{array}$ & $\begin{array}{r}<0.001 \\
0.048\end{array}$ & $\begin{array}{l}32 \cdot 8 \\
18 \cdot 0\end{array}$ & $\begin{array}{r}<0.001 \\
0.003\end{array}$ & $\begin{array}{l}25 \cdot 1 \\
12 \cdot 0\end{array}$ & $\begin{array}{l}0.003 \\
0.02\end{array}$ \\
\hline & Cumulative respirable & 4 & 23.6 & $<0.0001$ & $15 \cdot 5$ & 0.004 & $18 \cdot 6$ & $<0.001$ & $10 \cdot 6$ & 0.03 & - & \\
\hline & $\begin{array}{l}\text { exposure } \\
\text { Current respirable }\end{array}$ & 4 & - & & - & & - & & - & & $8 \cdot 6$ & $0 \cdot 07$ \\
\hline & Asbestos exposure & 1 & - & & $4 \cdot 1$ & 0.04 & - & & $4 \cdot 6$ & 0.03 & - & \\
\hline \multirow{6}{*}{$\begin{array}{l}\text { Terms not } \\
\text { included in } \\
\text { best fit model }\end{array}$} & $\begin{array}{l}\text { Age group } \\
\text { Cumulative respirable }\end{array}$ & $\begin{array}{l}4 \\
4\end{array}$ & $1 \cdot 8$ & $0 \cdot 8$ & $2 \cdot 7$ & $0 \cdot 6$ & $3 \cdot 0$ & $0 \cdot 6$ & $\underline{0.6}$ & $0 \cdot 96$ & $\begin{array}{l}7 \cdot 9 \\
6 \cdot 1\end{array}$ & $\begin{array}{l}0 \cdot 11 \\
0 \cdot 2\end{array}$ \\
\hline & $\begin{array}{l}\text { exposure } \\
\text { Cumulative inspirable }\end{array}$ & 4 & $9 \cdot 8$ & 0.04 & $7 \cdot 4$ & $0 \cdot 12$ & $18 \cdot 7$ & $<0.001$ & $2 \cdot 7$ & 0.06 & $6 \cdot 5$ & $0 \cdot 16$ \\
\hline & exposure & 4 & 9.0 & 0.04 & $1 \times$ & 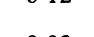 & 10 & 0000 & & 80 & ( & 80 \\
\hline & $\begin{array}{l}\text { Current respirable } \\
\text { exposure }\end{array}$ & 4 & $4 \cdot 8$ & $0 \cdot 3$ & $10 \cdot 4$ & 0.03 & $10 \cdot 0$ & 0.03 & $2 \cdot 8$ & 0.06 & - & \\
\hline & $\begin{array}{l}\text { Current inspirable } \\
\text { exposure level }\end{array}$ & 4 & $7 \cdot 8$ & $0 \cdot 10$ & $6 \cdot 0$ & $0 \cdot 2$ & $12 \cdot 5$ & 0.014 & $1 \cdot 7$ & $0 \cdot 8$ & $6 \cdot 2$ & $0 \cdot 2$ \\
\hline & Asbestos exposure & 1 & $1 \cdot 7$ & 0.07 & - & & $1 \cdot 1$ & $0 \cdot 3$ & - & & $0 \cdot 8$ & $0 \cdot 4$ \\
\hline
\end{tabular}

The deviances are those for the addition of the independent variable to the best fit regression relation.For the four exposure groups, one (and only one) was forced into each model; the corresponding deviances are those for adding the independent variable to the best fit set excluding any other exposure group.

smoked less. All the women were identified as having small opacity profusion $0 / 0$. So, the logistic regression analyses have been limited to men.

Of the 1005 men, 32 did not provide questionnaire information on smoking habits. Small opacity profusion is known to be related to tobacco smoking $^{31}$; so these men were also excluded from these further analyses. The number was therefore reduced to 973 .

Table 13 summarises the findings from the regression analyses. The best fit models were determined for various prevalences of small opacities. The independent variables were all grouped, rather than considered as continuous variables. For example, age was grouped into five classes: 15-24; $25-34 ; 35-44 ; 45-54$; and $55-64$. If the pattern of the regression coefficients is irregular, then this would indicate that the association is more likely to be due to chance.

The prevalence of any small opacities (category $0 / 1$ or higher) was significantly related to production plant, current smoking habits, and cumulative respirable exposure. The coefficients for the smoking groups increased with increasing daily amount smoked. The highest value for the exposure index gave the highest predicted value for the prevalence of small opacities.

A similar pattern was found for the prevalence of small opacities of category 1/0 or more. Exposure to asbestos, however, in the production plant also added significantly to the prediction. Figure 2 shows, for three plants, how the fitted prevalences increase with increasing exposure for a light smoker. The three plants were those with the highest, middle, and lowest prevalences. The other seven plants would form an identical pattern within the range in fig 2 and to aid clarity have not been drawn. The differences between plant prevalences may be due to such factors as genetic effects of the population from which the workforce was drawn, the nature of the material smoked (low to high tar),

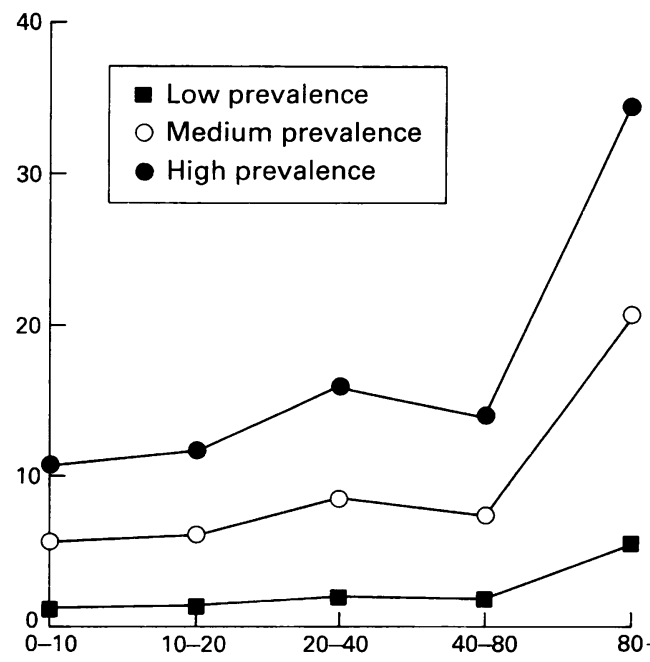

Cumulative respirable dust $\left(\mathrm{mg} \cdot\right.$ months $\cdot \mathrm{m}^{-3}$ )

Figure 2 Fitted prevalences for small opacities classified $1 / 0$ or greater in the three plants with the lowest, middle, and highest prevalences. 
depth of inhalation (rather than the quantity as this has been corrected), and perhaps a different healthy worker effect in different plants. Also, there could be some residual confounding between plant and other factors such as exposure.

For category $1 / 1$ or more, all the exposure indices are significant predictors. The statistical fit was marginally improved by including cumulative exposure to inspirable dust, rather than cumulative exposure to respirable dust, but the regression coefficients for cumulative exposure to respirable dust increased monotonically with increasing exposure.

Both rounded and irregular parenchymal opacities were reported, but the predominant pattern was of a mixture of both shapes. The primary shape was rounded for $63 \%$ of the films with profusion 1/0 or more. The logistic regression findings for these rounded cases only is similar to that for all films of prevalence at least $1 / 0$. The prevalence for the $37 \%$ with predominant irregular shape was less strongly associated with any of the independent variables, including current smoking habits. The current respirable exposure was the best predictor of the four exposure indices, but was not quite significant at the $5 \%$ level.

Poor film quality was a major cause of reader uncertainty in the ILO classifications, as recorded independently by the readers at the time of the reading. When the statistical analyses were recalculated, excluding 121 poor quality films (from the 10 included plants) that caused the greatest reader uncertainty, the associations noted in table 13 were strengthened. For all opacities of category $1 / 0$ or more, the association of small opacities with both cumulative and current respirable dust exposures become statistically significant predictors, standardised for each other.

Preliminary analysis of lung function indices against small opacities suggests a statistically significant association between abnormal chest $x$ ray films $\left(0 / 1\right.$ or greater) and lowered $\mathrm{FEV}_{1}(\mathrm{p}<0.05$, one tailed) and FVC $(p<0.01$, one tailed). The $\mathrm{FEF}_{25-75}$, however, showed an increase in those with abnormal $x$ ray films.

In summary, the analysis of respiratory symptoms, lung function, and the chest $x$ ray film appearance of small opacities show statistically significant associations with exposure to carbon black. The associations are stronger for current rather than cumulative exposure for symptoms and lung function but the reverse is true for radiographic change. The trend of increasing effect with increasing exposure to carbon black dust suggests that the effect may be caused by the exposure, although the radiographic changes probably indicate parenchymal deposition of carbon black dust rather than pathological change.

\section{Discussion}

The carbon black industry world wide has considerable economic and technical importance with the product having widespread use, although about $95 \%$ of production is used in the manufacture of automotive tyres. Some of these industries or their customers are known to have working environments, in the past at least, that have given rise to occupationally related excesses of cancer in their employee population. ${ }^{32}$ In the main carbon black is a pure powdered form of elemental carbon, to which is attached a number of inorganic elements and various metals ${ }^{33}$ and hydrocarbon complexes. ${ }^{5}$ It is the ability of the fine particles of carbon black to penetrate to the deeper regions of the lung and perhaps to exert a pathogenic effect on pulmonary function through diseases such as pneumoconiosis and chronic bronchitis that is of concern; although the known or suspect human carcinogenic hydrocarbon complexes adsorbed onto the carbon black are ultimately of greatest concern. ${ }^{25}$ It was the industry's own concern for these potential, but not substantiated, health effects that prompted the desire both in Europe and North America to undertake health surveys of the exposed workforce.

The present investigation was designed not only to provide more accurate estimates of exposure and health effects through careful and concurrent measurements but also to establish a cohort of workers that could be followed up prospectively for morbidity effects over a decade. The procedures used were not in themselves novel, it was the unique attempt to collect accurate, reputable, and reliable data across seven countries and in 18 plants that distinguished this report and produced the main difficulties in execution. The working population for its part is remarkably stable (annual turnover is about $5 \%$ ); thus a series of cross sectional studies is, in this case, capable of providing reasonably reliable longitudinal data that would not be possible with a high labour turnover with the inherent difficulty of following up the many leavers. Some of the ethical difficulties of undertaking mortality studies in some European countries are yet to be resolved, but for this report, the emphasis was on establishing a cohort of workers with carbon black and undertaking a valid cross sectional health effect and exposure study. Largely, this was achieved.

The study population eligible for inclusion at the start of the exercise was 3086 . The response rates from some plants were too low to allow valid interpretation and thus the study was ultimately restricted to 1742 (questionnaires) and 1720 (spirometry) employees from 15 plants, with an overall response rate of $81 \%$. For the chest $x$ ray films, response rates were poorer and this part of the analysis was restricted to 10 plants and 1096 radiographs with an overall response rate of $74 \%$. 
Therefore, the actual proportion studied of the total potential study population (3086), is about $56 \%$ for questionnaires and spirometry and about $36 \%$ for chest $x$ ray films. The effect of this is to reduce the statistical power of the study (the whole of western Europe was chosen to ensure sufficient numbers and power), but with the benefit of reducing potential bias (if plants with low participation had been included). It was unfortunate that the biggest plant in Europe (about 750 workers) was not able to provide sufficient samples within the time period, due to logistical difficulties, to qualify for inclusion in any part of the study.

The health measures were assessed from data gathered from validated and standard health questionnaires and the spirometry and radiography were conducted to internationally accepted guidelines. Unfortunately, as a result of logistical, time, and financial constraints, it was not possible for the study team to collect these data themselves. The prestudy training sessions, combined with periodic visits to the plants and a careful review of despatched materials with a request for repeats where the data were unacceptably poor, however, suggest that the data analysed were valid.

The assessment of exposure, based as it is on the (statistically) appropriate number of personal samples, provides the first comprehensive review of current workplace exposure in the carbon black production industry. In total, 5238 samples were taken, with about 1300 samples for respirable and inspirable dust as well as carbon monoxide and sulphur dioxide. As well as the statistical basis of the sampling strategy, this study gained valid measurements for both inspirable and respirable dust for the first time. The only other report on dust concentrations, published in $1982,{ }^{6}$ did not consider that there was a suitable means of measuring respirable dust. Unfortunately the $10 \mathrm{~mm}$ cyclone used in the United States and considered for the study in 1982 is made from nylon and suffers greatly from the effects of static electricity. The cyclone used in this study is the SIMPEDS cyclone, ${ }^{2627}$ and the filter is held in an aluminium cassette, which is not affected by static build up. The biological relevance of these two dust sampling heads is explained more fully in the papers by Ogden $^{34}$ and by Vincent and Mark. ${ }^{35}$

The data for the two measured gases were, in the main, below the limit of detection for the active colorimetric technique used. It was therefore not possible to generate either current or retrospective exposure indices. The results suggested that for most workers, their exposure to carbon monoxide or sulphur dioxide was neglible but occasionally an exposure approaching the occupational exposure limits was detected. ${ }^{4}$ Without the use of a different technique with a lower limit of detection, however, it is not possible to gain useful information about these contaminants. The number and provision of the dust samples has enabled the generation of both current and cumulative exposure indices. The use of current exposure to generate cumulative or retrospective indices of exposure is always of most concern in studies of this nature. Anecdotal reports and data from published papers suggest that exposure to carbon black was much higher in the past. Unfortunately, insufficient information of this type was available to the authors, and so the cumulative indices were generated by multiplying time of service in certain job categories by the relevant current geometric mean exposure and then if more than one job had been performed, these values were all added together. A value for every worker is ranked in ascending order and then suitable cut off points are made, this being repeated for both dust fractions. The technique as described, is likely to limit the upper range of cumulative values (mg.months. $\mathrm{m}^{-3}$ ), but it is not possible to assess accurately the degree of misclassification (the placement of a subject into an exposure group, either current or cumulative, to which they do not belong).

In the two main morbidity reports previously mentioned, ${ }^{13}{ }^{14}$ a lack of exposure data limited the exposure effect analysis. Robertson $e t a l^{14}$ only used measures of cumulative total dust and Crosbie ${ }^{13}$ estimated exposure simply by assigning a subject to a job title without taking any dust measurements. Neither author was therefore able to differentiate between the different size fractions of dust with Crosbie $^{13}$ unable to generate retrospective dust indices.

Respiratory symptoms were generally infrequent in this population and similar across the plants. Some confidence in the validity of the measures comes from the fact that these symptoms show the expected correlations with age and smoking habit. The prevalence of chronic phlegm and cough is comparable with that in the Crosbie study, ${ }^{13}$ but the prevalence of wheezing is lower in our study. It is not possible to make further comparison as the Crosbie study used a much shorter questionnaire, that precluded assessment of other symptoms such as chronic bronchitis and dyspnoea. Crosbie analysed the spirometry data by comparing smokers $v$ non-smokers; dust exposure $v$ no dust exposure; smokers with no dust exposure $v$ smokers with dust exposure, and non-smokers with no dust exposure $v$ non-smokers with dust exposure for each of the indices of lung function measured and creating a lung deterioration index. Each subject's index was calculated by dividing an arbitrary number given by the number of respirable symptoms ( 3 $=100,2=60,1=30$ and $0=1$ point) by the summation of the four percentage predicted values 
(FVC, $\mathrm{FEV}_{1}, \mathrm{MMEF}_{25-75}$ and $\mathrm{FEF}_{75-85}$ ). The use of this technique and the limited spirometry analyses previously mentioned makes comparison with that undertaken in our studies very difficult. Also, the use of routinely taken small format $x$ ray films over a two year period from the voluntary participants of 11 plants, and read by just one reader precludes the safe comparison of these radiographic data with that gained and reported here.

Unlike the study by Robertson et al in which no significant effect related to exposure was noted in their analysis of lung function (except cumulative total dust against mean \% predicted FVC without correcting for smoking), ${ }^{14}$ the study reported here found significant and increasing effects on $\mathrm{FEV}_{1}$ and $\mathrm{FEF}_{25-75}$ with current respirable dust exposure for never smokers ( $p<0.05$; table 10). More statistically significant effects were found for ex and current smokers $(p<0.01)$ although the magnitude of the decrement in the highest exposure group was about a third for smokers $(-0.125 \mathrm{l})$ compared with never $(-0.348 \mathrm{l})$ and ex smokers $(-0.364 \mathrm{l})$ for $\mathrm{FEV}_{1}$ and even less for $\mathrm{FEF}_{25-75}$ (smokers $-0.153 \mathrm{l}$, never smokers $-0.79 \mathrm{l}$, and ex-smokers -0.951 1). This might suggest an interaction, although antagonistic, between exposure to carbon black dust and smoking. As three separate regression equations were fitted for the different smoking groups, it is not possible to test the significance of a possible term of interaction.

As mentioned in the introduction, some health studies other than those of Crosbie ${ }^{13}$ and Robertson and coworkers ${ }^{14}$ have been conducted in workforces occupationally exposed to carbon black. The first, published in 1951 by Gartner and Brauss, investigated carbon black workers and coal miners in the Ruhr area and South Wales and identified 31 cases of radiographic changes analogous to pneumoconiosis. ${ }^{10}$ The association between exposure to carbon black and pneumoconiosis was confirmed in $1956^{11}$ and $1957^{12}$ by Meiklejohn who investigated a few cases of simple pneumoconiosis in employees with $30-50$ years of exposure in manufacturing (what was described as) soot $^{11}$ and two carbon black factories in the United Kingdom where three cases of pneumoconiosis out of 22 investigated in factory $A$ and five cases out of 20 in factory $B$ were identified. ${ }^{12}$ Miller and Ramsden reported a case of massive fibrosis and pneumoconiosis in a man exposed to carbon black in a rubber factory. ${ }^{36}$

In 1961, Kareva and Kollo investigated a manufacturing plant in Russia with a workforce of 89 and reported stage 1 pneumoconiosis in four $(4.5 \%)$ and suspect pneumoconiosis in 15 workers $\left(16.9 \%, 21.3 \%\right.$ overall). ${ }^{37}$ Further studies by Komarova and Rapis, ${ }^{38}$ and Komarova ${ }^{39}$ (on populations of 66 and 643) reported stage 1 pneumoco- niosis in seven out of 52 examined and radiological changes evaluated as pneumoconiosis in 18 of the same examined group. The second study seemed to report the same radiographic data. In 1970, Slepicka and coworkers described pneumoconiosis in nine out of 52 members of the workforce $(17 \cdot 3 \%))^{40}$

Three studies were published in 1975, by Troitskaya and coworkers, ${ }^{41}$ Valic and coworkers, ${ }^{42}$ and Wehr and coworkers. ${ }^{43}$ Troitskaya et al investigated a total population of 357 drawn from four factories with an overall prevalence of radiographic change of $4 \cdot 8 \%$, Valic et al investigated 35 carbon black workers and found a prevalence of radiographic change of $17 \cdot 1 \%,{ }^{42}$ and Wehr et al assessed 397 employees over six years and found a prevalence of $9.6 \%$ definite pneumoconiosis and lesser degrees of pneumoconiosis in $11 \%$ of the men and $2 \%$ of the women. ${ }^{43}$ Cocarla and coworkers found 29 cases of pneumoconiosis out of 143 subjects $(20.3 \%) .^{44}$ Two studies published in 1980 , the first by Kollo ${ }^{45}$ and the second by Beritic-Stahuljak and co-workers ${ }^{46}$ both reported significant increases in the prevalance of pneumoconiosis; no actual figures were given in the first but in the second in excess of $20 \%$ was reported. Finally, the most recent publication in 1985, by Beck and co-workers, found evidence of pneumoconiosis in all 13 patients involved in acetylene black manufacture. ${ }^{47}$ It is therefore apparent that the prevalence of radiographic changes found in our study is of the same order of magnitude as that of many of the other studies published (although few state what they considered "radiographic change") except, surprisingly, the study by Crosbie on roughly the same population as ours. This was possibly due to the use of small format films, known to give a lower proportion of abnormal readings, and only one reader. ${ }^{48}$

Some of the studies mentioned have also assessed respiratory symptoms. Komarova found $92 \%$ of a workforce of 80 had respiratory symptoms ${ }^{49}$ and more than $50 \%$ of a workforce of 643 reported respiratory symptoms with $30 \cdot 2 \%$ reporting bronchitis. ${ }^{39}$ Troitskaya and co-workers, ${ }^{41} \mathrm{Wehr}$ et $a l^{23}$, Kollo et $a l^{45}$ and Beritic-Stahuljak and coworkers, ${ }^{46}$ have all reported high prevalences of exposure related respiratory symptoms, seemingly greater than those found in our investigation.

Spirometry is the area in which the least amount of research has been completed and hence comparison with our investigation is limited. Komarova and $\mathrm{Rapis}^{38}$ and Komarova, ${ }^{39}$ reported that $27 \%$ of a workforce of $66 \mathrm{had}$ a significant decrement in initial capacity and $66 \%$ of the 51 subjects selected from a workforce of 643 showed functional changes. Troitskaya and coworkers, ${ }^{41} \mathrm{Wehr}$ and coworkers, ${ }^{43}$ Oleru and coworkers, ${ }^{50}$ and BeriticStahuljak ${ }^{46}$ all found exposure related decrements 
in $\mathrm{FEV}_{1}$ and FVC. The size of the decrement was rarely stated and so comparison is difficult.

Some of our results suggest that the carbon black is exerting a short term effect at the site of deposition, and the lack of cumulative effect may be due either to a retrospective exposure index that is too imprecise or to the effects of carbon black being acute and not chronic. The second phase of the study is underway, and we plan to investigate the potential effects of carbon black over time. This should be relatively easy, as most workers move from jobs of high exposure to those of a lesser exposure over time and it is also hoped to examine retirees. Further, a more detailed retrospective exposure index is proposed with questionnaires for both plant and individual participants.

\section{Conclusions}

Our study found a correlation between small opacity profusion and dust exposure. A similar exposure-effect relation was found for respiratory symptoms and spirometry.

The overall results of this survey indicate that exposure to carbon black dust is associated with some increased prevalence of respiratory symptoms, small decrements in lung function, and the accumulation of dust in the lungs. They are consistent with a non-specific irritant dust effect, but the planned follow up studies are required to explore further whether these exposures cause parenchymal lung damage as opposed to benign parenchymal deposition of carbon black.

1 Rivin D. Carbon Black. In: Hutzinger O, ed. The handbook of environmental chemistry. Berlin: Springer-Verlag, 1986;(Vol 3/Part D).

2 International Agency for Research on Cancer. Monographs on the evaluation of the carcinogenic risk of chemicals to humans. Vol 33. Polynuclear aromatic compounds, part 2, carbon blacks, mineral oils and some nitroarenes. Lyon: IARC, 1984.

3 Gardiner K, Trethowan WN, Harrington JM, Calvert IA, Glass DC. Occupational exposure to carbon black in its manufacture. Ann Occup Hyg 1992;36:477-96.

4 Gardiner $\mathrm{K}$, Trethowan WN, Harrington JM, Calvert IA, Glass DC. Occupational exposure to carbon monoxide and sulphur dioxide during the manufacture of carbon black. Ann Occup Hyg 1992;36:363-72.

5 Gardiner K, Hale KA, Calvert IA, Rice C, Harrington JM. The suitability of the urinary metabolite 1-Hydroxypyrene as an index of polynuclear aromatic hydrocarbon bioavailability from workers exposed to carbon black. Ann Occup Hyg 1992;36:681-8.

6 Smith RG, Musch DC. Occupational exposure to carbon black: a particulate study. Am Ind Hyg Assc $\mathcal{F}$ 1982; 43:925-30.

7 Bennecke $\mathrm{H}$. Carbon inhalation by animals. Pneumonologie 1906;6:139-48.

8 Leueke, AW. Epithelioma in carbon workers. The Cleveland Medical Fournal 1907;6:199-202.

9 Borchardt $\mathrm{H}$. Inhalation of various types of carbon dusts. Virochows Arch [A] 1929;271:366-76. (In German.)

10 Gartner $H$, Brauss FW. Gwerbe und unfallmedizin. Untersuchungen zur frage der russlunge und zur schaedlichkeit des reinen kohlenstaubanteiles in staub der kohlenberwerke. Die Medizinische 1951;8:253-5. (In German).

11 Meiklejohn A. In: Merewether ERA, ed. Industrial medicine and hygiene. London: Butterworth, 1956;3:103-5.

12 Meiklejohn A. Reports of the 12th international congress on occupational health. Helsinki: 1957;3:335-8.

13 Crosbie WA. The respiratory health of carbon black workers. Arch Environ Health 1986;41:346-53.

14 Robertson J McD, Diaz JF, Fyfe IM, Ingalls TH. A cross sectional study of pulmonary function in carbon black workers in the United States. Am Ind Hyg Assoc F 1988;49:161-6.

15 Ingalls. TH. Incidence of cancer in the carbon black industry. Archives of Industrial Hygiene and Occupational Medicine 1950;1:662-76.

16 Ingalls TH, Risques-Iribarren R. Periodic search for cancer in the carbon black industry. Arch Environ Health 1961;2: 429-33.

17 Robertson JMcD, Ingalls TH. A case control study of circulatory, malignant, and respiratory morbidity in carbon black workers in the United States. Am Ind Hyg Assoc f 1989; 50:510-5.

18 Hodgson JT, Jones RD. A mortality study of carbon black workers employed at five United Kingdom factories between 1974 and 1980. Arch Environ Health 1980;40: 261-8.

19 Troitskaya NA, Velichkovsky BT, Kogan FM, O'kuz'minukh AI. On carcinogenic hazards in the carbon black industry. Vopr Onoli 1980;26:63-67. (In Russian).

20 Teta J, Ott MG, Schnatter AR. Population based mortality surveillance in carbon black products manufacturing plants. Br F Ind Med 1987;44:344-50.

21 American Thoracic Society statement: standardization of spirometry-1987 Update. Am Rev Respir Dis 1987;136: $1285-98$.

22 International Labour Office. Guidelines for the use of ILO International classification of radiographs for pneumoconioses. Geneva: ILO 1980. Occupational Safety and Health Series No 22:48.

23 NIOSH. Criteria for a recommended standard occupational exposure to carbon black. Cincinnati: US Dept of Health, Education, and Welfare, Public Health Service, Centre for Disease Control, National Institute for Occupational Safety and Health, 1978. DHEW (NIOSH) Pub no 78-204.

24 Donnet JP, Voet AS. Carbon black; physics, chemistry and elastomer reinforcement. New York: Marcel Dekko Inc 1976.

25 International Standards Organization. Air quality-particle size fraction definitions for health related-related sampling. Geneva: International Standards Organization, 1983, Technical report $150,7708(\mathrm{E})$

26 Gwatkin G, Ogden TL. The SIMPEDS respirable dust sampler: side by side comparison with the 113A. Colliery Guardian 1979;60:326-31.

27 Blackford DB, Harris GW, Revell G. The reduction of dust losses within the cassette of the SIMPEDS personal dust sample. Ann Occup Hyg 1985;29:169-80.

28 Health and Safety Executive. General methods for the gravimetric determination of respirable and total dust. London: HMSO, Health and Safety Executive, 1986. (MDMS 14)

29 Mark D, Vincent JH. A new personal sample for airborne total dust in workplaces. Ann Occup Hyg 1986;30:89-102.

30 European Coal and Steel Community. Standardised lung function testing. Fournal of the Societas Europaea Physiologiae Clinicae Respiratoriae 1983;19(suppl 5):1-95.

31 Weiss W. Cigarette smoking and small irregular opacities. $\mathrm{Br}$ f Ind Med 1991;48:841-4.

32 International Agency for Research on Cancer. Evaluation of the carcinogenic risk of chemicals to humans. The rubber industry. Vol. 28 Lyon: IARC 1982.

33 Sokhi RS, Gray C, Gardiner K, Earwarker LG. PIXE analysis of carbon black for elemental impurities. Nuclear Instruments and Methods in Physics 1990;B49:414-7.

34 Ogden T. The ISO and ACGIH standardized size fractions and their relation to human deposition data. Ann Occup Hyg 1988;32(suppl 2):413-21.

35 Vincent JH, Mark D. On the biologically relevant sampling of airborne particles. Ann Occup Hyg 1988;32(suppl 1):423-34.

36 Miller AA, Ramsden F. Carbon pneumoconiosis. $\mathrm{Br} \mathcal{F}$ Ind Med 1961;18:103-13.

37 Kareva AI, Kollo RM. Roentgenological changes in the lungs under the effect of carbon black. Vestnik Rentgenologii $i$ Radiologii 1961;36:40-2. (In Russian.)

38 Komarova LT, Rapis BL. Some indices on the condition of the respiratory organs in carbon black workers. Nauchnye Trudy, Ormskii Meditsinski. Institut 1968;86:141-9. (In Russian.) 
39 Komarova LT. Hygienic evaluation of the production of carbon black by the furnace method. Gig Tr Prof Zabol 1973;17:32-6. (In Russian.)

40 Slepicka J, Eisler L, Mirejovsky P, Simecek R. Lung changes in workers due to long-term employment in the production of carbon black. Pracovni Lekarstvi 1970;22:276-81. (In Czechoslavakian.)

41 Troitskaya NA, Velichkovskii BT, Bikmullina SK, Sazhina TG, Corodnova NV, Andreyeva TD. Substantiation of the maximum permissible concentration of industrial carbon black in the air of production areas. Gigiena Truda $i$ Professional'nye Zabolevaniya 1975;17:32-6. (In Russian.)

42 Valic F, Beritic-Stahuljak D, Mark B. A follow-up study of functional and radiological lung changes in carbon black exposure. Internationales Archiv für Arbeitsmedizin 1975;34:51-63. (In German.)

43 Wehr KL, Johanson WG, Chapman JS, Pierce AK. Pneumoconiosis among activated carbon workers. Arch Environ Health 1975;30:578-82.

44 Cocarla A, Cornea G, Dengel H, Gabor S, Milea M, Papilian VV. Carbon black pneumoconiosis. Int Arch Occup Environ Health 1976;36:217-28. (In French.)

45 Kollo RM. A health evaluation of working conditions in a channel black plant. Trudy Leningradskogo SanitarnoGigienicheskogo 1980;62:128. (In Russian.)

46 Beritic-Stahuljak D, Cigula M, Rubala D, Valic F, Mark B. Changes in the respiratory system of carbon black workers over a period of fourteen years. Acta Medica Yugoslavia 1980;34:363-72. (In Russian.)

47 Beck B, Gohlke R, Sturm W, Bergmann L, Wolf E. Carbon black lung as an occupational disease. Z Erkrank Atm-Org 1985;164:254-66. (In German.)

48 Sheers G, Rossiter CE, Gilson JC, Mackenzie FAF. UK Naval dockyards asbestosis study: radiological methods in the surveillance of workers exposed to asbestos. $\mathrm{Br} F$ Ind Med 1978;35:195-203.

49 Komarova LT. The effect of air contamination in the production of carbon black on the morbidity and health of the workers. Nauchnye Trudy, Ormkii Meditsinski Institut 1965;61:115-21. (In Russian.)

50 Oleru UG, Elegbeleye OO, Enu CC, Olumide YM. Pulmonary function and symptoms of Nigerian workers exposed to carbon black in dry cell battery and tire factories. Environ Res 1983;30:161-8.

Accepted 22 February 1993 